\begin{tabular}{c} 
journal homepage: http://ijiemjournal. uns.ac.rs/ \\
International Journal of Industrial \\
Engineering and Management \\
Volume $12 /$ No 4 / December $2021 / 226-227$ \\
\hline
\end{tabular}

Editorial

\title{
EDITORIAL:
}

\section{New Horizon for Industrial Engineering and Management}

\author{
U. Marjanović
}

\author{
Editor-in-Chief, International Journal of \\ Industrial Engineering and Management \\ Professor of Industrial Engineering and Management \\ University of Novi Sad, \\ Faculty of Technical Sciences, \\ Novi Sad, Serbia \\ umarjano@uns.ac.rs
}

Another volume is behind us, with 24 papers discussing exciting topics in industrial engineering and management. The fourth Industrial Revolution has brought disruptive changes in academic research and industrial practices in manufacturing. The traditional methods of production and their supply chains affected by the latest technologies such as artificial intelligence will lead to more resilient, sustainable, and smart production. Manufacturing companies need to find an appropriate response to increase efficiency, reduce costs, improve agility and flexibility, and upgrade the responsiveness and resilience of their production operations. Indeed, the digital transformation of production has brought a new horizon, and the International Journal of Industrial Engineering and Management (IJIEM) will continue to serve researchers and practitioners in the industrial engineering, manufacturing engineering, and management fields.

In this editorial, I present the papers of Volume 14, Issue 4.

\section{The aim and structure of this Issue}

This Issue contains six articles. The first article is a literature review of all published papers in IJIEM from its establishment. The other five cover topics from process innovation technics, sustainability, rapid prototyping techniques, lean thinking, and maintenance management.

The first article studies the history of the International Journal of Industrial Engineering and Management by analyzing the topics that have received the most attention in each of the journal's publication years. In the article 'Research Trends and Topics in IJIEM from 2010 to 2020: A Statistical History', I. Spasojevic, S. Havzi, D. Stefanovic, S. Ristic, and U. Marjanovic present an analysis both summarized for all eleven years and individually for intervals of three years. They identified that information technologies in industrial engineering are becoming immensely popular in the last few years. 
M. Malindzakova, D. Malindzak, and P. Garaj present implementing the Single Minute Exchange of Dies (SMED) method within the case study company, a local subsidy of a global producer of hygiene products in the article 'Implementation of the Single Minute Exchange of Dies method for reducing changeover time in a hygiene production company.' The results are encouraging, showing that the SMED method is mandatory for companies struggling with frequent and prolonged changeover times.

In the article 'Selection of sustainable suppliers in the oil and gas industry using fuzzy multi-criteria decisionmaking methods,' K. Jermsittiparsert, M. Zahar, S. Sumarni, O. Y. Voronkova, S. Y. Bakhvalov, and R. Akhmadeev introduce the comprehensive framework for ranking and selecting sustainable suppliers in the oil and gas industry. The proposed framework results depict that the quality indicators of materials purchased from suppliers and commitment to contracts were ranked first and second among all criteria.

A comparative analysis among Additive (ARP) and Subtractive (SRP) rapid prototyping techniques, aiming to determine which approach presents greater technical and economic viability for physical prototype manufacturing are discussed and illustrated in the article 'Additive and subtractive rapid prototyping techniques: a comparative analysis of FDM \& CNC processes.' A. Neuenfeldt-Funior, M. Cheiram, M. Eckhardt, C, Scheuer, F. Siluk, and $M$ Francescatto used the Analytic Hierarchy Process multi-criteria decision method to categorize and quantify the analysis criteria. The SRP rapid prototyping technique is the most suitable alternative for manufacturing prototypes.

Lean Thinking is a well-known management philosophy that increases productivity and reduces cost by eliminating waste. As a contribution to the problems of diagnosing production systems, T. Afonso, A. C. Alves, P. Carneiro, and A. Vieira present 'Simulation pulled by the need to reduce wastes and human effort in an intralogistics project.' They focus on proposing the use of AGVs for materials handling and transport in certain shop-floor zones instead of using milkrun. They revealed the reduction of the supply machines' time and route time by half and the removal of human effort.

A new framework capable of responding effectively at the beginning of the implementation process of a Total Productive Maintenance system is applied in the article, 'Selecting the best tools and framework to evaluate equipment malfunctions and improve the OEE in the cork industry' by P. Marinho, D. Pimentel, $R$. Casais, F. Silva, F. C. Sá, and L. P. Ferreira. The paper outlines a novel application of tools in the correct sequence, allowing for solving some persistent problems in a few steps, resulting in significant gains for companies. 